\title{
Xylem structure and function in three grapevine varieties
}

\author{
Constanza Quintana-Pulido ${ }^{1}$, Luis Villalobos-Gonzālez ${ }^{1}$, Mariana Muñoz ${ }^{1}$, Nicolās Franck ${ }^{1}$, \\ and Claudio Pastenes ${ }^{{ }^{*}}$
}

${ }^{1}$ Universidad de Chile, Facultad de Ciencias Agronómicas, Casilla 1004, Santiago, Chile. *Corresponding author (cpastene@uchile.cl).

Received: 12 April 2018; Accepted: 20 July 2018; doi:10.4067/S0718-58392018000300419

\begin{abstract}
Xylem vessels are responsible for conducting water, in a metastable state, to the transpiring leaves. As tension increases, hydraulic failure may occur. At any given tension, the resistance of the xylem vessels to cavitation depends on their morphology, of which vessels diameter has been pointed out as relevant. Grapevines (Vitis vinifera L.) are often cultivated in Mediterranean climates and mostly under controlled water deficit conditions. Besides, a high variability in the stomatal sensitivity exists in different varieties. 'Cabernet Sauvignon' (CS) is recognized as isohydric, 'Syrah' (S) as anisohydric, and no clear information exist for 'Carménère' (C), an important grapevine variety for the Chilean wine industry. In the present study, xylem morpho-anatomical traits from stems in CS, S, and C, growing in a single vineyard, were analyzed, inferring their specific theoretical hydraulic conductivity. Also, the maximal hydraulic conductivity and vulnerability to cavitation, the latter expressed as the xylem water potential reducing a $50 \%$ loss in hydraulic conductivity $\left(\mathrm{PLC}_{50}\right)$ were assessed in stems collected from the field. Higher vessels diameter was found in S and C, followed by CS, in general ranging from 21 to $120 \mu \mathrm{m}$, resulting in an expected proportional theoretical hydraulic conductivity of nearly 40 to $43 \mathrm{~kg} \mathrm{~s}^{-1} \mathrm{~m}^{-1} \mathrm{MPa}^{-1}$ in $\mathrm{C}$ and $\mathrm{S}$, and merely $23 \mathrm{~kg} \mathrm{~s}^{-1} \mathrm{~m}^{-1} \mathrm{MPa}^{-1}$ in $\mathrm{C}$. This values were similar -but not proportionally- to maximal actual hydraulic conductivity measured in stems with median values, in average, of 28, 17, and $13 \mathrm{~kg} \mathrm{~s}^{-1} \mathrm{~m}^{-1} \mathrm{MPa}^{-1}$ in S, C, and CS, respectively. Even though wider xylem vessels have been correlated with higher xylem vulnerability to cavitation, PLC $_{50}$ was significantly higher in S (-2.3 MPa) compared to C (-1.1 MPa), and even though xylem vessels diameter were similar between $\mathrm{S}$ and $\mathrm{C}, \mathrm{C}$ was as vulnerable as CS. We found no such tradeoff between hydraulic efficiency and vulnerability.
\end{abstract}

Key words: Grapevines, PLC $_{50}$, specific theoretical hydraulic conductivity, Vitis vinifera, xylem morphology.

\section{INTRODUCTION}

In plants, the water lost from evaporative tissues, mainly green leaves, is replaced by that taken up from the soil, and conducted through the xylem conduits, under negative tension in a metastable state. The extent of the tension force in the xylem vessels results, apart from the xylem architecture, from the water potential gradient between the soil and the water demanding air and is strongly modulated by the resistances along the water stream, of which stomata is of major importance. As the tension increases, heterogeneous cavitation is likely to occur in trees due to the expansion of dissolved air within water (Cochard et al., 2013), which, in turn, might fill the whole vessel, forming embolism. An embolized vessel is non-transporting (Tyree and Sperry, 1988).

One controversial aspect on water stress resistance to cavitation events in plants is the xylem morphology. The xylem security on one hand, as well as the efficiency for water transport, has been both largely correlated with the 
morphoanatomy of the xylem vessels (Wheeler et al., 2005). The xylem vessels size has been long thought to be of importance on the occurrence of embolism at a given tension and also with the hydraulic conductivity properties in plants (Lovisolo and Schubert, 1998) and both are, physically, opposite (Tombesi et al., 2014). Even though in the agricultural context grapevines are considered as water stress resistant species, compared to wild species in natural environments are highly susceptible and characterized by long as well as wide xylem vessels (Choat et al., 2010). In a study involving 120 woody species (Jacobsen and Pratt, 2012), it was found that xylem vessels in stems of Vitaceae are wider and longer than the $94.4 \%$ of those studied but, still, a high variability has been observed on the xylem architecture between grapevine varieties (Schultz, 2003; Hochberg et al., 2015). Furthermore, in grapevines as well as other species it has been observed that wider xylem vessels have higher water conductivity levels but, also, are prone to cavitation events (Hargrave et al., 1994; Hochberg et al., 2015) suggesting a tradeoff between xylem hydraulic efficiency and vulnerability to cavitation, i.e. smaller vessels size prevents excessive water loss by reducing xylem conductivity, but preventing embolism (Lovisolo and Tramontini, 2010). These evidence however, which has led to the so called safety-efficiency hypothesis, has been challenged by a study involving 335 angiosperms in which the correlation between xylem safety and efficiency appears to be rather weak (Gleason et al., 2015).

Even though the xylem morphoanatomic properties have been controversial in terms of its incidence on hydraulic failure, reductions in both, the xylem vessel cross section area and vessels diameter, have been observed in grapevines upon water stress conditions (Lovisolo et al., 1998). Therefore, there is still the question whether xylem properties, such as xylem cross section area and prevailing vessels diameter is of importance in grapevines in the context of their vulnerability to cavitation.

In grapevines, water stress is a usual field practice for high quality wine making and the identification of convenient traits for early selection programs is of paramount importance in many Mediterranean climate-producing areas. Furthermore, in the context of a global climate change in which water is becoming scarce, as it is in major vineyard plantation areas in Chile, a better understanding on the basis for water stress resistance is of great interest. In the present study, we assessed the xylem morphoanatomic properties from three grapevine varieties important for the Chilean red wine industry: Cabernet Sauvignon, Syrah, and Carménère, comparing their theoretical and actual hydraulic efficiency properties, in relation to their vulnerability to cavitation. 'Cabernet Sauvignon' has been reported as a near isohydric variety and, on the contrary, 'Syrah' is recognized as near anisohydric (Schultz, 2003; Hochberg et al., 2013; Tramontini et al., 2014; Jara et al., 2017). According to observations relating stomatal conductance upon water supply in 'Carménère', this variety seems to behave rather as near-isohydric (Pastenes et al., 2014).

\section{MATERIAL AND METHODS}

\section{Xylem morphology and calculations}

The plant material was taken from a single vineyard, from 'Syrah' (S), 'Carménère' (C), and 'Cabernet Sauvignon' (CS) plants, all of them located close to each other, in similar soil conditions and irrigation regimes. All the three varieties were 7 to $11 \mathrm{yr}$ old, own rooted and yielding 9 to $11 \mathrm{t} \mathrm{ha}^{-1}$. During pruning time, three different plants were selected in five different areas on each block, corresponding to a variety. Plants were similar in vigor. From each plant, two stems were cut from the base and taken to laboratory. All the varieties were trained to a vertical trellising system, with shoots oriented upwards.

In the laboratory, the primary shoots grown in the season were cut under water, leaving a $30 \mathrm{~cm}$ segment, nearly 35 to $40 \mathrm{~cm}$ from the base of the shoot. These were perfused with a solution of $10 \mathrm{mM} \mathrm{KCl}$ and $1 \mathrm{mM} \mathrm{CaCl}_{2}$ in filtered and degassed distilled water, for approximately $6 \mathrm{~h}$, to eliminate any type of embolism existing in the segment. Subsequently, they were injected with silicone RTV-141 A and B (Rhodia, Cranbury, New Jersey, USA) in a ratio of 10:1, and mixed with $1 \%(w / w)$ uvitex (Ciba Uvitex OB, Ciba Specialty Chemicals, Tarrytown, New York, USA), under pressure of $0.12 \mathrm{MPa}$ for $24 \mathrm{~h}$. Samples were sectioned for analysis into 20 to $30 \mu \mathrm{m}$ sections with a vertical microtome (Reichert, Wien, Austria). Cross-sections were observed using a compound microscope (BA310, Motic, Hong Kong, China) at 40X magnifications, a charge-coupled device camera (Moticam 1080, Motic) and image software (Motic Images Plus 2.0). With the ImageJ software (Image Java, New York, USA), a representative portion of the xylem of each image was selected and analyzed. The area of the selected xylem portion, and the number and area of vessels were determined (80- 
180 vessels). The cross-sectional area of each vessel was used to calculate an equivalent circle diameter, assuming the diameter of a circle with the same area as the measured vessel (Scholz et al., 2013).

The theoretical hydraulic conductivity $\left(\mathrm{K}_{\mathrm{h}}, \mathrm{kg} \mathrm{s}^{-1} \mathrm{~m}^{-1} \mathrm{MPa}^{-1}\right)$ was calculated by a modification of the Hagen-Poiseuille law (Tyree and Ewers, 1991) as follows:

$$
k_{h}=\left(\frac{\pi \mathrm{p}}{128_{\eta}}\right) \sum_{i=1}^{n}\left(d_{i}^{l}\right)
$$

The specific theoretical hydraulic conductivity of xylem $\left(\mathrm{K}_{\mathrm{tx}}, \mathrm{kg} \mathrm{s}^{-1} \mathrm{~m}^{-1} \mathrm{MPa}^{-1}\right)$, was calculated by normalizing $K_{h}$ by the xylem area.

For the analysis of the distribution of the xylem vessels, frequency classes of $20 \mu \mathrm{m}$ vessel diameter were performed. The number of vessels per xylem area $\left(\mathrm{mm}^{2}\right)$, relative frequency, specific theoretical hydraulic conductivity of xylem $\left(\mathrm{K}_{\mathrm{tx}}\right)$, accumulated $\mathrm{K}_{\mathrm{tx}}$ and percentage of the total $\mathrm{K}_{\mathrm{tx}}$, for each kind of vessel diameter frequency, were calculated. Curves of the accumulated specific theoretical hydraulic conductivity were generated, totalizing the $\mathrm{K}_{\mathrm{tx}}$ of each successive diameter class, from the smallest size to the largest diameter classes.

Three cross-sections per shoot were photographed with a 40X magnifying glass (Motic), and then analyzed using the ImageJ software. The area of the stem occupied by the xylem was calculated by subtracting, from the cross-sectional area, the area occupied by the pith (parenchyma) and the outer portion of the xylem (phloem), considering the set as a circular section.

\section{Vulnerability curves (VC)}

We generated vulnerability curves using the bench top drying technique. Briefly, whole shoots were sampled between 12:00 and 16:00 $\mathrm{h}$ at the end of the season; these shoots were cut at their bases, covered with two black plastic bags, and stored in a wet expanded polystyrene (Styrofoam) and transported to the lab. These shoots were later air dried for between $0 \mathrm{~h}$ and $6 \mathrm{~h}$ at room temperature under lab lights $\left(<10 \mu \mathrm{mol} \mathrm{m} \mathrm{m}^{-2} \mathrm{~s}^{-1} \mathrm{PAR}\right)$ before $\Psi_{\text {stem }}$ values were measured. Shoot percent loss in hydraulic conductivity (PLC) in each case was then recorded.

We measured PLC using a XYL'EM high-resolution liquid mass flow meter (xylem embolism meter, Instrutec, Montigny les Cormeilles, France) as described in previous work (Cochard et al., 2013). The shoots were cut under tap water at least the ninth internode from the basal end. The cut end was then covered with parafilm, transferred to clean distilled water, and cut again using a fresh razor blade. A solution of $10 \mathrm{mM} \mathrm{KCl}$ and $1 \mathrm{mM} \mathrm{CaCl}_{2}$ in distilled, filtered, and degassed water (Milli-Q, Merck, Darmstadt, Germany) was then used to perfuse stem segments. Shoots were carefully attached to the tubes of the XYL'EM device under a column of water flowing at a pressure less than $7 \mathrm{kPa}$. Subsequently, shoots were then cut successively from their distal ends to leave two successive internodes, or a segment, larger than $8 \mathrm{~cm}$ before leaf blades and petioles were cut from the stem. Values for Ks were then measured in stem segments following the method of Tyree and Zimmermann (2002). In this study $\mathrm{K}$ was defined as follows:

$$
K=F / \Delta P \Delta l
$$

In this expression, $F\left(\mathrm{~kg}\right.$ water $\left.\mathrm{s}^{-1}\right)$ refers to the mass flux of the perfusion solution, while $\Delta P$ is the water pressure difference along the length of the stem segment (MPa), and $\Delta l$ is stem segment length (m). Finally, $K$ was normalized to stem cross-sectional area in order to obtain $\mathrm{Ks}\left(\mathrm{kg} \mathrm{s}^{-1} \mathrm{~m}^{-1} \mathrm{MPa}^{-1}\right)$, with corresponding PLC calculated, as follows:

$$
P L C=100\left(1-K s / K s_{\max }\right)
$$

In this expression, $K s_{\max }$ denotes maximum $K s$ obtained by flushing segments for $5 \mathrm{~min}$ at a minimum of $0.12 \mathrm{MPa}$ to remove any pre-existing air embolisms.

By means of the silicon infiltration technique, we concluded that no more than $10 \%$ of the xylem vessels were larger than $8 \mathrm{~cm}$ in all the varieties and besides the fact that after 6 hours the whole length shoots being kept in darkness reached leaf water potential values of nearly $0.5 \mathrm{MPa}$, suggests that probability for the open vessels artifact was minimum.

\section{Data analysis}

The data obtained from the different morphoanatomical variables of the xylem were analyzed by an ANOVA. In the case of significant differences between cultivars, the data were subjected to a multiple comparison test using the Fisher LSD test, considering a level of significance of 5\%. The data obtained from the distribution of the xylem vessels were transformed into a log-quotient transformation (McElrone et al., 2004). Then, an analysis of the multivariate variance was 
performed. When the test was significant, a Hotelling test corrected for the Bonferroni inequality was performed, in order to compare mean vectors between groups, considering a level of significance of $\mathrm{p} \leq 0.05$.

We fitted our vulnerability curve data to an exponential sigmoidal equation (Pammenter and Vander Willigen, 1998), as follows:

$$
\text { PLC }=100 /\left(1 / \exp \left(\text { slope }_{50}\left(\Psi_{\text {stem }}-P_{50}\right)\right)\right)
$$

In this expression, slope $e_{50}$ and $P_{50}$ refer to the slope and $\Psi_{\text {stem }}$ after $50 \%$ conductivity loss, respectively. Nonlinear least squares estimates of parameters from this model were determined using the Gauss-Newton algorithm (Bates and Chambers, 1992), and vulnerability curve parameters were tested for significant differences using bootstrapped confidence intervals (CIs) $(\mathrm{n}=999$ bootstrap replicates).

\section{RESULTS}

As shown in Table 1, the stem cross section of CS and C were nearly a 30\% significantly higher than that of S. Similarly, the xylem cross section was also significantly higher in CS and C, compared to S, but in nearly a $40 \%$. In addition, a lesser proportion of the stem was destined to xylem tissues in S, as observed by the xylem cross section to stem cross section ratio, with an average value 10\% lower compared to that of CS and C (Table 1). On the other hand, a similar number of xylem vessels per xylem area were observed in the three cultivars, but $\mathrm{S}$ having a significantly higher average vessel area per xylem area, at least compared to CS (Table 2). Furthermore, S resulted with a higher total area of vessels per xylem area, followed by $\mathrm{C}$ and, finally, with the lowest value, by CS (Table 2). Accordingly, the higher values for the xylem specific theoretical hydraulic conductivity were observed in S, in average nearly a $56 \%$ higher than the values for CS. As for $\mathrm{C}$, an intermediate xylem specific theoretical hydraulic conductivity was found, with nonsignificant differences with $\mathrm{S}$ and CS (Table 3).

Significant differences in the vessels distribution were observed between the cultivars C and S, when compared to CS, even though, for all of them, the vessel distribution peaked at a vessel area of 61-80 $\mu \mathrm{m}$ (Figure 1A). Still, when comparing the relative frequency distribution of vessels per each diameter class, no significant differences were observed between the three varieties (Figure 1B). Also, a lower number of vessels higher than $80 \mu \mathrm{m}$ occurred in CS (33\%) compared to $\mathrm{C}(41 \%)$ and $\mathrm{S}(43 \%)$ (Figure 1B). The higher number of wider vessels in $\mathrm{C}$ and $\mathrm{S}$ resulted in a concomitant higher theoretical specific (to xylem area) conductivity $\left(\mathrm{K}_{\mathrm{tx}}\right)$ according to the Hagen Poiseuille equation -where the radius of the

Table 1. Stem cross-section, xylem-cross section and their corresponding ratio in 'Cabernet Sauvignon', 'Carménère' and 'Syrah'.

\begin{tabular}{|c|c|c|c|}
\hline Cultivar & $\begin{array}{c}\text { Stem cross } \\
\text { section (SCS) }\end{array}$ & $\begin{array}{c}\text { Xylem cross } \\
\text { section (XCS) }\end{array}$ & $\mathrm{XCS} / \mathrm{SCS}$ \\
\hline & \multicolumn{2}{|c|}{$\mathrm{mm}^{2}$} & - \\
\hline Cabernet Sauvignon & $43.59 \pm 1.58 \mathrm{a}$ & $22.15 \pm 0.87 \mathrm{a}$ & $0.51 \pm 0.005 \mathrm{a}$ \\
\hline Carménère & $45.26 \pm 1.16 \mathrm{a}$ & $23.27 \pm 0.76 a$ & $0.51 \pm 0.008 \mathrm{a}$ \\
\hline Syrah & $34.59 \pm 1.59 b$ & $15.76 \pm 0.89 b$ & $0.45 \pm 0.007 \mathrm{~b}$ \\
\hline $\mathrm{P}$ value & 0.014 & 0.003 & 0.004 \\
\hline
\end{tabular}

Different letters in the same column indicate differences according LSD test (at the P value indicated in the bottom row) between treatments.

Table 2. Number of vessels, average vessels area and total area of vessels per xylem cross-section in 'Cabernet Sauvignon', 'Carménère' and 'Syrah'.

\begin{tabular}{lccc}
\hline Cultivar & $\begin{array}{c}\text { Nr vessels } \\
\mathrm{mm}^{-2}\end{array}$ & $\begin{array}{c}\text { Average vessels } \\
\text { area } \mathrm{mm}^{-2}\end{array}$ & $\begin{array}{c}\text { Total area of } \\
\text { vessels } \mathrm{mm}^{-2}\end{array}$ \\
\hline Cabernet Sauvignon & $34.52 \pm 0.95$ & $0.0020 \pm 0.00012 \mathrm{~b}$ & $0.14 \pm 0.005 \mathrm{c}$ \\
Carménère & $37.91 \pm 1.46$ & $0.0024 \pm 0.00021 \mathrm{ab}$ & $0.18 \pm 0.012 \mathrm{~b}$ \\
Syrah & $41.61 \pm 1.21$ & $0.0030 \pm 0.00013 \mathrm{a}$ & $0.20 \pm 0.005 \mathrm{a}$ \\
\hline P value & 0.12 & 0.01 & 0.0001
\end{tabular}

Different letters in the same column indicate differences according LSD test (at the P value indicated in the bottom row) between treatments. 
Table 3. Xylem specific theoretical hydraulic conductivity $\left(\mathbf{K}_{\mathrm{tx}}\right)$ in stems of 'Cabernet Sauvignon', 'Carménère' and 'Syrah'.

\begin{tabular}{cc}
\hline Cultivar & $\mathrm{K}_{\mathrm{tx}}$ \\
\hline & $\mathrm{kg} \mathrm{MPa}^{-1} \mathrm{~s}^{-1} \mathrm{~m}^{-1}$ \\
Cabernet Sauvignon & $23.8 \pm 0.37 \mathrm{~b}$ \\
Carménère & $33.5 \pm 0.51 \mathrm{ab}$ \\
Syrah & $42.4 \pm 0.39 \mathrm{a}$ \\
\hline P value & 0.013 \\
\hline
\end{tabular}

Different letters in the same column indicate differences according LSD test (at the $\mathrm{P}$ value indicated in the bottom row) between treatments.

Figure 1. Total number of vessels per xylem cross-section (A) and relative frequency (B) per vessels diameter classes in 'Cabernet Sauvignon' (CS), 'Carménère' (C) and 'Syrah' (S).

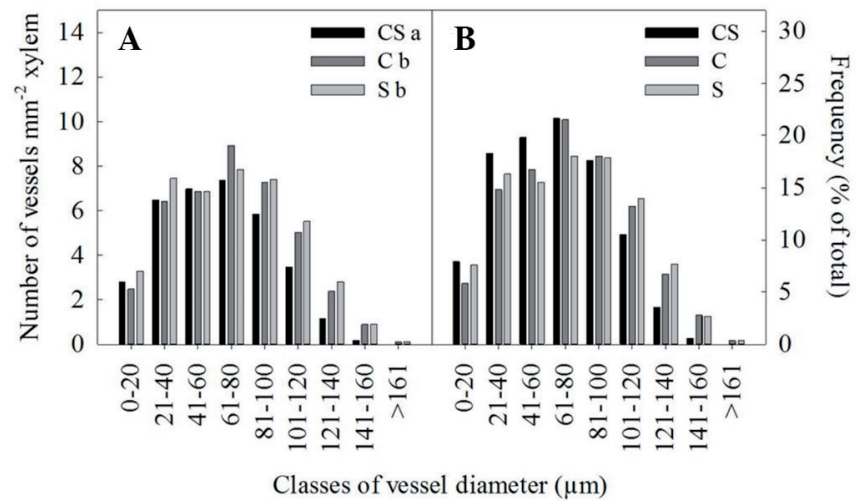

Different letters indicate differences significant at the 0.05 probability level, according to the Hotelling (Bonferroni) test.

Figure 2. Specific theoretical hydraulic conductivity of the xylem $\left(K_{t x}\right)(A)$ and cumulated xylem specific theoretical hydraulic conductivity (B) per vessel diameter classes in stems of Cabernet Sauvignon (CS), Carménère (C) and Syrah (S).

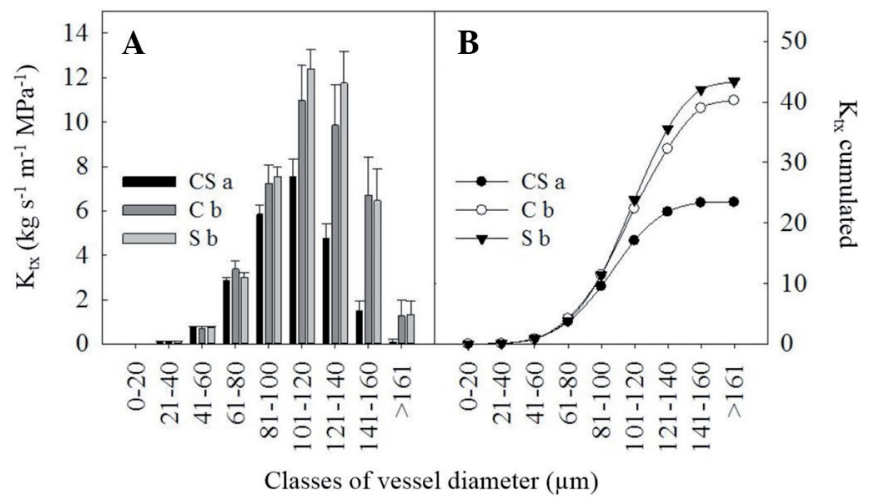

Different letters indicate differences significant at the 0.05 probability level, according to the Hotelling (Bonferroni) test. 
Figure 3. Xylem specific theoretical hydraulic conductivity $\left(K_{t x}\right)$ as percentage from the total (A) and cumulated $K_{\mathrm{tx}}$ as percentage $(B)$ per vessel diameter classes in stems of 'Cabernet Sauvignon' (CS), 'Carménère' (C) and 'Syrah' (S).

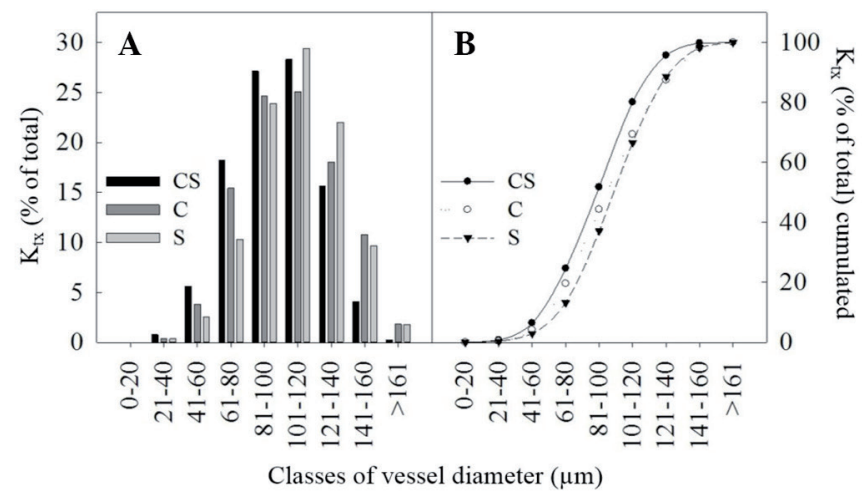

Figure 4. Maximal xylem hydraulic conductivity $\left(K_{h}\right)$ assessed in stems of 'Cabernet Sauvignon' (CS), 'Carménère' (C) and 'Syrah' (S).

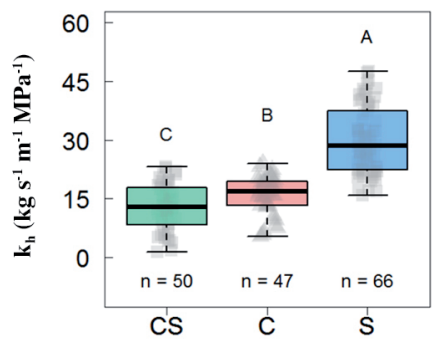

Different letters indicate differences according LSD test at the $\mathrm{P}<0.05$ between treatments

Figure 5. (A) Vulnerability curves showing percent loss in hydraulic conductivity (PLC) as a function of xylem pressure in shoots $\left(\Psi_{\text {Stem }}\right)$ of the 'Cabernet Sauvignon' $(C S)$, 'Carménère' $(C)$, and 'Syrah' (S) grapevine varieties. Gray arrows indicate $\mathbf{P}_{50}$ estimates for each variety. B: Boxplot of $\mathbf{P}_{50}$ from bootstrapping analysis for each variety. $C$ : Boxplot of slope 50 from bootstrapping analysis for each variety.

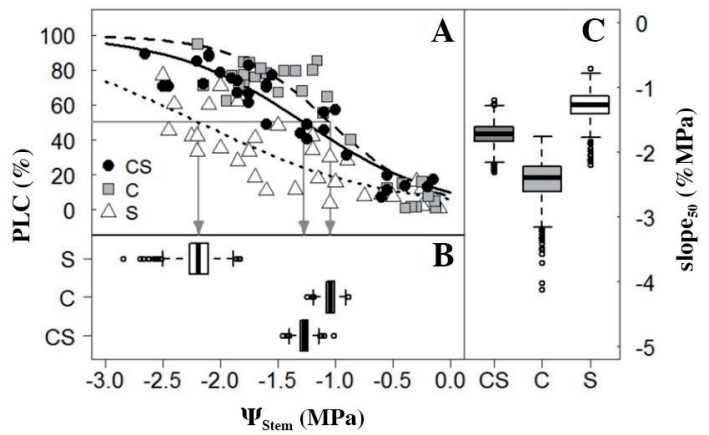

Each point corresponds to a single stem; data include at least 30 of each variety. 
pipe goes to the fourth power- (Figure 2A), reaching cumulated values of $43.4 \mathrm{~kg} \mathrm{~s}^{-1} \mathrm{~m}^{-1} \mathrm{MPa}^{-1}$ in S and $40.2 \mathrm{~kg} \mathrm{~s}^{-1} \mathrm{~m}^{-1}$ $\mathrm{MPa}^{-1}$ in C, both significantly higher than $23.4 \mathrm{~kg} \mathrm{~s}^{-1} \mathrm{~m}^{-1} \mathrm{MPa}^{-1}$ in CS (Figure 2B). As for the relative theoretical hydraulic conductivity $\left(\mathrm{K}_{\mathrm{tx}}\right)$, nonsignificant differences were observed on the vessels distribution between varieties (Figure 3A). Even though the xylem vessels smaller than $60 \mu \mathrm{m}$, corresponding to a $46 \%$ in CS, 37\% in C and 39\% in S, were an important proportion of the total amount of xylem vessels (Figure 3A), they contributed to a rather small percentage of the theoretical cumulated $\mathrm{K}_{\mathrm{tx}}: 6 \%, 4 \%$ and $3 \%$ for Cs, C and S, respectively (Figure 3B).

When assessing the actual hydraulic conductivity of stems $\left(\mathrm{K}_{\mathrm{h}}\right)$ from the same plants than those used for morphological observations, this time all the varieties significantly differed one from each other with a median of nearly 29,17 , and $13 \mathrm{~kg} \mathrm{~s}^{-1} \mathrm{~m}^{-1} \mathrm{MPa}^{-1}$ for S, C, and CS, respectively (Figure 4). Even though the $\mathrm{K}_{\mathrm{tx}}$ and $\mathrm{K}_{\mathrm{h}}$ values range up to a similar extent, the proportions do not necessarily match. First, a much wider difference is observed between $\mathrm{S}$ and $\mathrm{C}$, the former reaching an actual value 70\% higher than the latter (Figure 5), compared to the merely $7 \%$ difference from the theoretical calculation (Figure 2B). The actual $\mathrm{K}_{\mathrm{h}}$ value of $\mathrm{S}$ is nearly a 130\% higher than CS (Figure 4), again much higher than the $85 \%$ difference when considering the theoretical $\mathrm{K}_{\mathrm{h}}$ (Figure $2 \mathrm{~B}$ ). On the opposite, the theoretical $\mathrm{K}_{\mathrm{h}}$ difference between $\mathrm{C}$ and CS was approximately $72 \%$ higher for the former, but only $36 \%$ higher when comparing the actual $\mathrm{K}_{\mathrm{h}}$ values.

In order to compare the xylem anatomy as well as the theoretical and actual stem hydraulic conductivity with the hydraulic safety, a vulnerability curve was built for all the grapevine varieties, as shown in Figure 5. The curves in Figure 5 show that stem vulnerability was lower in the S variety, followed by CS and C (Figure 5A). Slope and $\Psi_{\text {stem values at }}$ $50 \%$ PLC bootstrap analyses suggest that the stems of S variety grapevines are significantly less vulnerable to cavitation than their CS and C counterparts. Indeed, bootstrapping P50 mean values for the S, CS, and C varieties were -2.2, -1.27, and -1.04 MPa, respectively (Figure 5B). In contrast, sensitivities to changes in $\Psi_{\text {stem }}$ at the $50 \%$ loss point (slope 50 ) were nonsignificantly different between the stems of $\mathrm{S}, \mathrm{CS}$, and $\mathrm{C}$ varieties, with bootstrapping mean values of $-1.28 \% \mathrm{MPa}^{-1}$, $-1.73 \% \mathrm{MPa}^{-1}$, and $-2.43 \% \mathrm{MPa}^{-1}$, respectively (Figure 5C).

\section{DISCUSSION}

We have assessed the stem xylem morphology in three grapevine varieties: Cabernet Sauvignon, Carménère, and Syrah, grown in a commercial vineyard under similar soil and irrigation conditions, confirming previous observations on the high variability in the stem xylem properties in grapevines (Schultz, 2003), with potential implications on the hydraulic conductivity. As observed before, $\mathrm{K}_{\mathrm{tx}}$ is positively correlated with the number of vessels per xylem cross-section area and the vessels diameter (Tyree and Zimmermann, 2002). The three varieties had a similar number of xylem vessels per xylem cross section area, but the higher $\mathrm{K}_{\mathrm{tx}}$ values in $\mathrm{S}$ and $\mathrm{C}$ (Table 2) resulted from the higher proportion of wider vessels (Figure 2A), implying a greater capacity for water transport on a xylem area basis as compared to CS (Figure 2B). Also, the higher efficiency in S seems to allow a smaller xylem cross-section area or a lower fraction of sapwood in stems in this variety, suggesting that the xylem is far more carbon cost effective compared to C and CS (Petit et al., 2016; Eller et al., 2017). It has to be underlined that the vessel diameter found in the present study is similar to previously reported in different grapevine varieties (Pagay et al., 2015; Petit et al., 2016).

Even though all the varieties studied were lower in their actual $\mathrm{K}_{\mathrm{h}}$ as compared to that theoretically calculated, in C the $K_{t x}$ is close to that of $S$ (Table 3), while the observed $K_{h}$ value is rather closer to CS (Figure 4), but in both cases intermediate to CS and $\mathrm{S}$. $\mathrm{K}_{\mathrm{tx}}$ assessed by means of the Hagen-Poiseuille law is known to overestimate the actual conductivity since vessels are not strictly cylindrical and variations in the diameter occurs along the vessels (Tyree and Zimmermann, 2002). Also, the presence of non-hydraulically functional vessels (containing gels or tyloses) and the presence of nodes (Pagay et al., 2015), which reduces conductivity, might explain the difference between the theoretical and the actual hydraulic conductivity (Jacobsen et al., 2015), as it occurs in our observations and calculations (Figures 2 and 4). The abovementioned causes for the differences between the theoretical and the actual $\mathrm{K}_{\mathrm{h}}$, might be of particular importance in $\mathrm{C}$.

The relationship between the hydraulic conductivity and their xylem architectural properties in different plant species and varieties have been largely discussed in terms of their implications on the physiology of water relations and stomata functioning, the efficiency for water transport to the evaporative sites and, very important, the resistance of the xylem vessels to water deficit. Regarding stomata, the terms iso- and anisohydric describes the stomatal responses to water 
shortages in higher plants (Tardieu and Simonneau, 1998), and various grapevine varieties have been identified in such continuum (Schultz, 2003; Palliotti et al., 2009), even though a great deal of controversy still exist when the iso/anishydric behavior has been assessed in grapevines. In general, it has been suggested that isohydric plants tend to have a more vulnerable xylem (Tombesi et al., 2014; Bartlett et al., 2016) and, as protection, tend to close their stomata earlier during drought than plants that have more embolism resistant xylem to cavitation (Meinzer et al., 2009). According to our PLC 50 curves, there is no evidence suggesting a higher xylem vulnerability to embolism in the near-anisohydric $\mathrm{S}$ variety.

Previous observations correlating xylem vessel diameter to hydraulic failure (Hargrave et al., 1994) (Cai and Tyree, 2010) has led to the general view that a compromise must exist between hydraulic efficiency and vulnerability in xylem vessels. Besides, in theory, large and long xylem vessels are highly conductive but more vulnerable to embolism. From our results, there seems to be a lack of correlation between predominant xylem vessels diameter and xylem vulnerability to hydraulic failure since S, a variety with a $43 \%$ frequency of vessels higher than $80 \mu \mathrm{m}$, compared to a mere $33 \%$ in $\mathrm{CS}$, is significantly more resistant according to $\mathrm{PLC}_{50}$ determinations than the latter. Recently, a meta analysis by Gleason et al., (2015) has shown a poor correlation between xylem hydraulic efficiency and safety across 335 angiosperm and 89 gymnosperm species. It is likely, therefore, that other xylem traits, apart from the xylem vessels diameter, are important on their vulnerability. Number of pits, total pits area, pit structure as well as size of largest inter-conduit pores have been suggested as important in the vulnerability to cavitation (Choat et al., 2004; Wheeler et al., 2005; Christman et al., 2009; Brodersen et al., 2013; Knipfer et al., 2018) and might be of importance in grapevines.

\section{CONCLUSIONS}

In general, a better knowledge on the basis for the plant resistance to either permanent or transient water shortages is of great importance in fruit production, as well as vineyards for wine purposes. Some anatomical traits in xylem vessels have thought to be relevant in both, the efficiency for water transport upon a given demand, and on the resistance to hydraulic failure. According to our results, involving three red grapevine cultivars important for the wine industry in Chile, and with contrasting stomatal sensitivity to drought, the xylem diameter on stems and their theoretical hydraulic conductivity gives a good indication on the stem maximal hydraulic conductivity, but both are not necessarily proportional. In addition, the theoretical sensitivity of stems with wider xylem vessels to cavitation does not occur in the varieties studied.

\section{ACKNOWLEDGEMENTS}

The authors thank the funding from CONICYT (FONDECYT Project $\mathrm{N}^{\circ} 1140880$ ). Also, the PAI program from CONICYT, scholarship T7816120001, and the short visit funding support VID from the Universidad de Chile. We are grateful to Viñedos Emiliana for the plant material and the field support given, particularly to Andrés Aparicio and the Department of I+D+i. We appreciate the enormous help from Magda Orell for her technical support.

\section{REFERENCES}

Bartlett, M.K., Klein, T., Jansen, S., Choat, B., and Sack, L. 2016. The correlations and sequence of plant stomatal, hydraulic, and wilting responses to drought. Proceeding of the National Academy of Sciences of United States of America 113:1309813103. doi:10.1073/pnas.1604088113.

Bates, D.M., and Chambers, J.M. 1992. Nonlinear models. p. 421-454. In Chambers, J.M., and Hastie, T.J. (eds.) Statistical Models in S. Wadsworth \& Brooks/Cole, Pacific Grove, California, USA.

Brodersen, C.R., McElrone, A.J., Choat, B., Lee, E.F., Shackel, K.A., and Matthews, M.A. 2013. In vivo visualizations of drought-induced embolism spread in Vitis vinifera. Plant Physiology 161:1820-1829. doi:10.1104/pp.112.212712.

Cai, J., and Tyree, M.T. 2010. The impact of vessel size on vulnerability curves: Data and models for within-species variability in saplings of aspen, Populus tremuloides Michx. Plant, Cell and Environment 33:1059-1069. doi:10.1111/j.13653040.2010.02127.x.

Choat, B., Drayton, W.M., Brodersen,C., Matthews, M.A., Shackel, K.A., Wada, H.I.R., et al. 2010. Measurement of vulnerability to water stress-induced cavitation in grapevine: A comparison of four techniques applied to a long-vesseled species. Plant, Cell and Environment 33:1502-1512. doi:10.1111/j.1365-3040.2010.02160.x. 
Choat, B., Jansen, S., Zwieniecki, M.A., Smets, E., and Holbrook, N.M. 2004. Changes in pit membrane porosity due to deflection and stretching : the role of vestured pits. Journal of Experimental Botany 55:1569-1575. doi:10.1093/jxb/erh173.

Christman, M.A., Sperry, J.S., and Adler, F.R. 2009. Testing the "rare pit" hypothesis for xylem cavitation resistance in three species of Acer. New Phytologist 182:664-674. doi:10.1111/j.1469-8137.2009.02776.x.

Cochard, H., Badel, E., Herbette, S., Delzon, S., Choat, B., and Jansen, S. 2013. Methods for measuring plant vulnerability to cavitation: A critical review. Journal of Experimental Botany 64:4779-4791.

Eller, C.B., Barros, F. de V., Bittencourt, P.R.L., Rowland, L., Mencuccini, M., and Oliveira, R.S. 2017. Xylem hydraulic safety and construction costs determine tropical tree growth. Plant, Cell and Environment 41:548-562. doi:10.1111/pce.13106.

Gleason, S.M., Westoby, M., Jansen, S., Choat, B., Hacke, U.G., Pratt, R.B., et al. 2015. Weak tradeoff between xylem safety and xylem- specific hydraulic efficiency across the world's woody plant species. New Phytologist 209:123-136. doi:10.1111/nph.13646.

Hargrave, K.R., Kolb, K.J., Ewers, F.W., and Davis, S.D. 1994. Conduit diameter and embolism (Labiatae) in Salvia mellifera . New Phytologist 126:695-705.

Hochberg, U., Degu, A., Fait, A., and Rachmilevitch, S. 2013. Near isohydric grapevine cultivar displays higher photosynthetic efficiency and photorespiration rates under drought stress as compared with near anisohydric grapevine cultivar. Physiologia Plantarum 147:443-52. doi:10.1111/j.1399-3054.2012.01671.x.

Hochberg, U., Degu, A., Gendler, T., Fait, A., and Rachmilevitch, S. 2015. The variability in the xylem architecture of grapevine petiole and its contribution to hydraulic differences. Functional Plant Biology 42(4):357-365.

Jacobsen, A.L., and Pratt, R.B. 2012. No evidence for an open vessel effect in centrifuge-based vulnerability curves of a longvesselled liana (Vitis vinifera). New Phytologist 194:982-990. doi:10.1111/j.1469-8137.2012.04118.x.

Jacobsen, A.L., Rodriguez-Zaccaro, F.D., Lee, T.F., Valdovinos, J., Toschi, H.S., Martinez, J.A., et al. 2015. Functional and ecological xylem anatomy. Perspectives in Plant Ecology, Evolution and Systematics 4(2):97-115. doi:10.1007/978-3-319-15783-2.

Jara, J., Holzapfel, E.A., Billib, M., Arumi, J.L., Lagos, O., and Rivera, D. 2017. Effect of water application on wine quality and yield in 'Carmenere' under the presence of a shallow water table in Central Chile. Chilean Journal of Agricultural Research 77:171-179 doi:10.4067/S0718-58392017000200171.

Knipfer, T., Barrios-Masias, F.H., Cuneo, I.F., Bouda, M., Albuquerque, C.P., Brodersen, et al. 2018. Variations in xylem embolism susceptibility under drought between intact saplings of three walnut species. Tree Physiology 00:1-13. doi:10.1093/treephys/tpy049.

Lovisolo, C., and Schubert, A. 1998. Effects of water stress on vessel size and xylem hydraulic conductivity in Vitis vinifera L. Journal of Experimental Botany 49:693-700. doi:10.1093/jxb/49.321.693.

Lovisolo, C., Schubert, A., Leonardo, V., Grugliasco, I., Arboree, C., and Miglioramento, C. 1998. Effects of water stress on vessel size and xylem hydraulic conductivity in Vitis vinifera L. Journal of Experimental Botany 49:693-700.

Lovisolo, C., and Tramontini, S. 2010. Methods for assessment of hydraulic conductance and embolism extent in grapevine organs. p. 71-85. In Delrot, S., Medrano, H., Or, E., Bavaresco, L., and Grando, S. (eds.) Methodologies and results in grapevine research. Springer, Dordrecht, The Netherlands. doi:10.1007/978-90-481-9283-0_6.

McElrone, A.J., Pockman, W.T., Martínez-Vilalta, J., Jackson, R.B., and McElrone, A.J. 2004. Variation in xylem structure and function in stems and roots of trees to $20 \mathrm{~m}$ depth. New Phytologist 163:507-517.

Meinzer, F.C., Johnson, D.M., Lachenbruch, B., McCulloh, K.A., and Woodruff, D.R. 2009. Xylem hydraulic safety margins in woody plants: Coordination of stomatal control of xylem tension with hydraulic capacitance. Functional Ecology 23:922930. doi:10.1111/j.1365-2435.2009.01577.x.

Pagay, V., Zufferey, V., and Lakso, A.N. 2015. The influence of water stress on grapevine (Vitis vinifera L.) shoots in a cool, humid climate: growth, gas exchange and hydraulics. Functional Plant Biology 43:827-837. doi:10.1071/FP16017.

Palliotti, A., Silvestroni, O., and Petoumenou, D. 2009. Photosynthetic and photoinhibition behavior of two field-grown grapevine cultivars under multiple summer stresses. American Journal of Enology and Viticulture 60:189-198.

Pammenter, N.W., and Vander Willigen, C. 1998. A mathematical and statistical analysis of the curves illustrating vulnerability of xylem to cavitation. Tree Physiology 18:589-593.

Pastenes, C., Villalobos, L., Ríos, N., Reyes, F., Turgeon, R., and Franck, N. 2014. Carbon partitioning to berries in water stressed grapevines: The role of active transport in leaves and fruits. Environmental and Experimental Botany 107:154-166.

Petit, G., Savi, T., Consolini, M., Anfodillo, T., and Nardini, A. 2016. Interplay of growth rate and xylem plasticity for optimal coordination of carbon and hydraulic economies in Fraxinus ornus trees. Tree Physiology 36:1310-1319. doi:10.1093/treephys/tpw069.

Scholz, A., Klepsch, M., Karimi, Z., and Jansen, S. 2013. How to quantify conduits in wood? Frontiers in Plant Science 4:56. doi:10.3389/fpls.2013.00056.

Schultz, H.R. 2003. Differences in hydraulic architecture account for near- isohydric and anisohydric behaviour of two fieldgrown Vitis vinifera L. cultivars during drought. Plant, Cell and Environment 28(8):1393-1405.

Tardieu, F., and Simonneau, T. 1998. Variability among species of stomatal control under fluctuating soil water status and evaporative demand: modelling isohydric and anisohydric behaviours. Journal of Experimental Botany 49:419-432. doi:10.1093/jxb/49.Special_Issue.419. 
Tombesi, S., Nardini, A., Farinelli, D., and Palliotti, A. 2014. Relationships between stomatal behavior, xylem vulnerability to cavitation and leaf water relations in two cultivars of Vitis vinifera. Physiologia Plantarum 152(3):453-464. doi:10.1111/ppl.12180.

Tramontini, S., Düring, J., Vitali, M., Ferrandino, A., Stoll, M., and Lovisolo, C. 2014. Soil water-holding capacity mediates hydraulic and hormonal signals of near-isohydric and near-anisohydric Vitis cultivars in potted grapevines. Functional Plant Biology 41(11):1119-1128. doi:10.1071/FP13263.

Tyree, M.T., and Ewers, F.W. 1991. The hydraulic architecture of trees and other woody plants. New Phytologist 119:345-360. doi:10.1111/j.1469-8137.1991.tb00035.x.

Tyree, M.T., and Sperry, J.S. 1988. Do woody plants operate near the point of catastrophic xylem dysfunction caused by dynamic water stress? Answers from a model. Plant Physiology 88:574-580. doi:10.1104/pp.88.3.574.

Tyree, M.T., and Zimmermann, M.H. 2002. Xylem structure and the ascent of sap. Springer Series in Wood Science. Springer Berlin Heidelberg, Berlin, Germany. doi:10.1007/978-3-662-04931-0.

Wheeler, J.K., Sperry, J.S., Hacke, U.G., and Hoang, N. 2005. Inter-vessel pitting and cavitation in woody Rosaceae and other vessel led plants: A basis for a safety versus efficiency trade-off in xylem transport. Plant, Cell and Environment 28:800-812. doi:10.1111/j.1365-3040.2005.01330.x. 